\title{
O USO DA REPETIÇÃO NA ESCRITA PELOS SURDOS
}

\author{
Wagner Teobaldo Lopes de Andrade* \\ Marígia Ana de Moura Aguiar** \\ Francisco Madeiro***
}

Resumo: A escrita é uma importante forma de comunicação dos surdos tanto com seus pares quanto com os ouvintes, dada a sua dificuldade em desenvolver a oralidade. Por estarem as marcas de oralidade diretamente relacionadas à coesão textual, este estudo objetivou investigar o uso de repetições na escrita de surdos. Quinze surdos oralizados, quinze surdos não-oralizados e quinze ouvintes responderam a um questionário analisado quantitativa e qualitativamente em função da ocorrência, tipologia, forma, posição e função das repetições. Os três grupos utilizaram a repetição na escrita. Os dois grupos de surdos apresentaram, majoritariamente, baixa frequência na repetição, integral e adjacente, na escrita. Os oralizados realizaram mais repetições com função de compreensão, enquanto que os não-oralizados realizaram-nas, especialmente, com função de continuidade tópica. Conclui-se que, tal como acontece com os ouvintes, a relação oralidade/ escrita ocorre nos surdos, mesmo que eles não tenham tido acesso natural à oralidade da lingua. E esta relação ocorre independentemente de eles serem oralizados ou não.

Palavras-chave: Fala. Escrita. Repetição. Surdez:

\section{INTRODUÇÃO}

O mundo dos surdos não tem som. Não há como ouvir os sons da comunicação sem o uso da tecnologia, o que dificulta ou, muitas vezes, impossibilita o falar. Mas a comunicação natural existe através da língua de sinais. A linguagem é diferente, feita com as mãos e o corpo.

Sabe-se que o conhecimento e uso funcional da língua de sinais por ouvintes é ainda uma utopia na realidade brasileira. Assim, a comunicação entre os surdos e ouvintes tem acontecido de forma mais efetiva através da escrita. No entanto, é fato que os surdos (com perda auditiva de grau severo e profundo) apresentam dificuldade em aprender a ler e escrever em língua portuguesa, o que tem explicitamente chamado

\footnotetext{
* Professor Assistente I do Departamento de Fonoaudiologia da Universidade Federal da Paraíba. Mestre em Ciências da Linguagem pela Universidade Católica de Pernambuco. Doutorando em Linguística pela UFPB. Email: wagner_teobaldo@yahoo.com.br

* Professora doutora do Mestrado em Ciências da Linguagem da Universidade Católica de Pernambuco. Pesquisadora do CNPq. Email: marigia.aguiar@gmail.com

*** Professor doutor do Mestrado em Ciências da Linguagem da UCPe. Email: madeiro@dei.unicap.br
} 
a atenção dos educadores, profissionais responsáveis pelo desenvolvimento e aprendizagem das habilidades de escrita nos anos iniciais de escolarização. Hoje, com a concepção de língua de sinais como primeira língua para a população surda e instrumento de acesso ao conhecimento do mundo, a modalidade escrita assume o papel de alternativa à instrução formal e uma das fontes de conhecimento da cultura ouvinte, na qual o surdo também se insere.

Em geral, os pais de crianças surdas costumam referir que as dificuldades de aprendizagem, especialmente da escrita (na língua padrão do país), são um problema secundário em relação à aquisição da linguagem oral. Isto, no entanto, pode tomar grandes proporções se tivermos em mente que uma criança surda, além de apresentar grandes dificuldades ou, algumas vezes, não desenvolver a fala, aprende a ler apenas pequenos textos, frases simples, e apresenta inúmeras complicações na escola.

As habilidades de escrita são um importante complemento para a língua de sinais e para a aquisição do conhecimento dos estudantes surdos. É quase impossível imaginar alguém que se oponha à afirmação de que todo cidadão tem o direito de participar da vida social, política e econômica da nação. Da mesma maneira, todos parecem partilhar do sentimento de que é responsabilidade da escola dar ao cidadão o instrumental mínimo para que ele exerça seu direito de avançar profissional e socialmente.

Tendo em vista a dificuldade que os surdos apresentam em desenvolver a língua oral, o presente estudo parte da constatação da grande importância da escrita para estes sujeitos. Além de ser o continuum oralidade-escrita um agente determinante e transformador da língua (CALADO, 2004) e esta ser, em sua modalidade oral, muitas vezes, de difícil utilização pelos surdos, a escrita na língua padrão do país, como já referido, torna-se um instrumento importante para a inserção desse indivíduo na sociedade e um meio importante de registro de ideias e pensamentos (QUADROS, 1993).

A relação entre a oralidade e a escrita é consensual na literatura, no entanto, até o presente momento, não foram encontrados estudos que identifiquem esta relação nos surdos, sujeitos que não possuem acesso natural à modalidade oral da língua. Desta forma, a pergunta 
norteadora deste estudo é: o fato de ser oralizado faz com que o surdo utilize mais marcas de oralidade, especialmente repetições, na sua escrita (tenha um texto mais coeso) do que o surdo não-oralizado, mesmo não utilizando a língua oral de forma corrente? Além disso, o estudo inclui, ainda, a pesquisa do uso de repetição em ouvintes, que servirá como parâmetro para a análise das repetições dos surdos oralizados e nãooralizados, tendo em vista que não são conhecidos estudos que refiram parâmetros para a análise da variável "repetição na escrita".

Sabendo que os surdos podem apresentar seu funcionamento linguístico marcado pelo uso exclusivo da oralidade, uso exclusivo da língua de sinais ou uso de ambas, o objetivo deste estudo foi investigar a ocorrência de repetições na escrita em língua portuguesa de estudantes surdos (de grau severo e profundo) e comparar os achados aos de ouvintes de mesmo grau de escolaridade.

Ressalta-se que, apesar de a língua de sinais ser a língua mais utilizada pelos surdos para a comunicação interpessoal com outros surdos e ouvintes conhecedores desta língua, este estudo tem seu foco voltado para a língua portuguesa, nas modalidades oral e escrita.

\section{REFERENCIAL TEÓRICO}

Este trabalho assume como pressuposto o conceito apresentado por Marcuschi $(2001,2005)$ de que a língua é muito mais um conjunto de práticas discursivas do que somente uma série de regras ou um sistema de formas simbólicas. Nessa perspectiva, a língua se manifesta e funciona como atividade oral e como atividade escrita.

Para Marcuschi (1995, 2004) e Cavalcante e Marcuschi (2005), a fala e a escrita, enquanto práticas interativas e complementares no contexto das práticas sociais e culturais, não devem ser tratadas de forma estanque e dicotômica. Marcuschi (2004) destaca que a oralidade e a escrita são práticas e usos da língua com características próprias que permitem a construção de textos coesos e coerentes, a elaboração de raciocínios abstratos e exposições formais e informais, variações estilísticas, sociais e dialetais, entre outras. O uso da língua, segundo Marcuschi (2005), ocorre num continuum de relações entre modalidades, gêneros textuais e contextos socioculturais. 
Apesar de se considerar a existência de diferenças entre o falar e o escrever, neste trabalho foi considerada a perspectiva de análise de Collins e Michaels (1991) e Marcuschi (1998, 2004), segundo os quais a fala e a escrita não formam dois extremos, mas um continuum distribuído numa escala de parâmetros empiricamente detectáveis, cuja identificação permite a inferência de que as características presentes na fala podem estar presentificadas também na escrita.

$\mathrm{Na}$ visão de Marcuschi (1995), é mais razoável olhar a relação entre a fala e a escrita sob o aspecto das características de cada modalidade do que apenas das diferenças. Desta forma, as modalidades falada e escrita da língua devem ser analisadas em função das suas relações de semelhança e diferença dentro de um quadro de categorias da mesma ordem de observação de fenômenos, pois alguns destes fenômenos atribuídos à fala ou à escrita não são próprios de uma ou outra, mas propriedades gerais da própria linguagem enquanto fenômeno social (MARCUSCHI, 1998, 2004, 2005).

A partir da proposta marcuschiana de que a relação entre a fala e a escrita se funda num continuum, é de se esperar que características de uma modalidade linguística estejam presentes na outra. Desta forma, tendo em vista a importância da coesão textual para os surdos pela dificuldade que experimentam em desenvolver a língua oral e, consequentemente, produzir a escrita de textos na língua padrão, as marcas de oralidade, por estarem diretamente relacionadas à coesão do texto, podem ser um elemento auxiliar do processo de organização textual, proporcionando maior coesividade ao texto produzido pelo surdo.

Segundo Marcuschi (2002), a repetição é uma das principais marcas de oralidade, e aí representa uma das estratégias de formulação textual mais presentes. De acordo com Silva (2001), o fenômeno linguístico da repetição desempenha um papel crucial desde as primeiras etapas da aquisição da linguagem e da socialização. Marcuschi (1997, p. 97) define funcionalmente esta marca de oralidade como "a produção de segmentos discursivos idênticos ou semelhantes duas ou mais vezes no âmbito de um mesmo evento comunicativo". De Tannen (1985) afirma ainda a repetição contribui para o estabelecimento do envolvimento entre os interlocutores nos aspectos de produção e compreensão conversacional. 
Jubran (2006) salienta que a repetição, como estratégia, pode introduzir, reintroduzir, manter ou delimitar tópicos. Este aspecto é, primordialmente, uma prova da naturalidade do texto oral e uma característica essencial não só da interação verbal, mas também da produção linguística resultante dessa interação verbal, seja ela dialógica ou monológica (MARCUSCHI, 2002).

Por apresentar uma maleabilidade funcional, a repetição assume um variado conjunto de funções: pode dar ênfase; reiterar um fato; contribuir para a organização discursiva e a monitoração da coerência textual; favorecer a coesão e a geração de sequências mais compreensíveis; dar continuidade à organização tópica e auxiliar nas atividades interativas (MARCUSCHI, 2006). As repetições, desta forma, atuam em vários planos: da coesividade, da compreensão, da continuidade tópica, da argumentatividade e da interatividade (MARCUSCHI, 1997, 2006).

Tannen (1985) e Marcuschi (2006) afirmam que, na escrita, o processo de revisão e editoração com apagamentos sucessivos diminui bastante a presença das repetições. Estes autores ressaltam, ainda, que a repetição não é um descontinuador do texto, mas representa uma estratégia de composição textual e condução do tópico discursivo.

Quanto à distribuição na cadeia textual, Marcuschi (2006) diz que a repetição pode ser adjacente (quando o termo repetido se encontra contíguo ou próximo à matriz) ou distante, quando, por exemplo, um item é repetido alguns tópicos adiante. Além disso, as repetições podem ocorrer de forma integral, quando o termo repetido é idêntico à matriz, ou com variação ou transformação (TANNEN, 1985). A repetição exata na oralidade, segundo Koch et al. (2002), é um fenômeno relativamente raro de acontecer, pelo fato de a entonação, na maioria das vezes, ser diferente mesmo quando se expressam as mesmas palavras.

Sabendo-se que, em função da falta de feedback auditivo, o surdo pode apresentar alteração no desenvolvimento fonológico, vocabulário receptivo e expressivo, sintaxe e morfologia, além da compreensão (SANTOS; NAVAS, 2002), a escrita e, especialmente, a coesão textual, se configura em uma habilidade imprescindível para a comunicação desses sujeitos. A repetição, neste contexto, apresenta-se como uma das estratégias linguísticas de que pode dispor o sujeito para promover maior coesão ao seu texto. 
A literatura em Audiologia Educacional e Educação Especial destaca, entre as filosofias para a educação do surdo, o oralismo e o bilinguismo, que tem como objetivo proporcionar o desenvolvimento pleno de suas capacidades (LACERDA, 1998).

A corrente oralista tem como pressuposto que as crianças surdas devem desenvolver como primeira forma comunicativa a língua oral (HARRISON; LODI; MOURA, 1997), enfatizando esta língua em termos terapêuticos (COUTO-LENZI, 1997). Segundo Perdoncini (1996), o oralismo apresenta um profundo desejo de sempre pensar nas crianças surdas em termos de audição. A filosofia oralista tem como objetivo fazer a reabilitação da criança surda em direção à normalidade $\mathrm{e}$ é considerada uma imposição social de uma maioria linguística (os ouvintes) sobre uma minoria linguística (os surdos) sem expressão diante da comunidade ouvinte (SÁNCHEZ, 1990; LANE, 1992; FERREIRABRITO, 1993; SKLIAR; MASSONE; VEINBERG, 1995; BUENO, 1998).

Perdoncini e Couto-Lenzi (1996) afirmam que às crianças surdas falta o sentido auditivo e a função auditiva. Por isso, os estudiosos e profissionais que realizam o oralismo costumam chamar as crianças de "deficientes auditivas" ou, simplesmente, "deficientes". A surdez, de forma semelhante, é chamada de "deficiência auditiva". Nesta concepção, a criança não é vista como um surdo, mas um sujeito que pode perceber sons (PERDONCINI, 1996). Esta perspectiva encontra base no fato de que a grande maioria das crianças surdas apresenta algum tipo de resíduo auditivo, dificilmente utilizado naturalmente. Segundo Couto-Lenzi (1997), os surdos de grau severo e profundo têm audição residual aproveitável, o que significa a possibilidade de atingir os sons da fala. Este potencial auditivo, no entanto, é otimizado através da protetização auditiva e de uma adequada estimulação terapêutica (ou educação auditiva) em direção à fala.

No entanto, os resultados dessas tentativas de oralização se mostraram frágeis ao longo dos anos. Considerando, então, que a maior parte das crianças com surdez profunda adquire apenas fragmentos linguísticos através da linguagem oral, um número cada vez maior de profissionais defende o modelo de educação bilíngue, que se diferencia do modelo oralista por considerar o canal visuogestual como fundamentalmente importante para a aquisição da linguagem da criança surda (LACERDA, 1998). 
Esta proposta pressupõe que os surdos desenvolvam competência em duas línguas: a língua padrão do país (no caso do Brasil, o português) e a língua de sinais, que é uma língua de modalidade visuogestual (SANTOS; DIAS, 1998), multicanal (uso da face, olhos, cabeça, corpo e mãos) (FELIPE, 1988) e um sistema linguístico independente do sistema de línguas orais (QUADROS, 1997), ao qual se equivale em qualidade e importância (CICCONE, 1996).

Para os defensores dessa corrente, a língua de sinais é importante para o surdo, permitindo-lhe um desenvolvimento de linguagem satisfatório em termos de efetividade comunicativa (QUADROS, 1997). Além disso, a exposição à língua portuguesa, seja na modalidade oral ou escrita, promoveria o desenvolvimento linguístico do ouvinte (SALLES et al., 2004). A língua de sinais, por outro lado, passa a atuar como um estigma, na medida em que evidencia a surdez.

O bilinguismo permite duas formas de implantação (dependendo da segunda língua utilizada pelo surdo), coincidentes apenas quanto à primeira língua (L1): a língua de sinais (GOLDFELD, 2002; SOUZA, 1998; FERNANDES, 2003). A segunda língua (L2), no caso do Brasil, corresponde à língua portuguesa (FERNANDES, 1990), seja na modalidade oral e escrita ou apenas escrita.

A língua de sinais, para os surdos, assim como o português falado para os ouvintes, fornecerá todo o aparato linguístico-cognitivo necessário à utilização de estratégias de interpretação e produção de textos escritos (BRASIL, 1997). O seu objetivo é que a criança surda possa ter um desenvolvimento linguístico-cognitivo adequado, assim como acontece na criança ouvinte, e que possa desenvolver uma relação harmoniosa também com ouvintes, tendo acesso a duas línguas: a de sinais e a do grupo majoritário (LACERDA, 2000).

Desta forma, posicionamo-nos favoravelmente ao bilinguismo como filosofia educacional para o desenvolvimento da linguagem do surdo, assim como à perspectiva de análise da sua escrita sob o ponto de vista da coesão e da coerência, sem nos prendermos a possíveis equívocos que os sujeitos possam apresentar na área da morfologia ou da sintaxe.

Acreditamos que esta postura favorecerá o desenvolvimento da escrita do surdo, pois teremos como foco o conteúdo e não apenas a forma, que, apesar de importante, não deve ser priorizada no processo de escolarização desses sujeitos. 


\section{METODOLOGIA}

\subsection{PARTICIPANTES}

O presente estudo foi realizado em uma escola da rede pública da cidade de Recife/PE, onde ocorre o ensino integrado entre surdos e ouvintes. Na escola, existiam, no ano de 2006, 34 alunos surdos nas turmas diurnas e noturnas do Ensino Médio. Intérpretes de língua de sinais atuam na sala de aula fazendo a interpretação desta língua para o português e vice-versa, facilitando a comunicação entre surdos e ouvintes.

Participaram do estudo 45 sujeitos de ambos os sexos, entre 17 e 38 anos de idade, estudantes do Ensino Médio. Destes, 15 são ouvintes e 30 são surdos bilíngues, que apresentam surdez de grau severo ou profundo bilateral e pré-lingual (antes dos três anos de idade, segundo MONREAL et al., 1995). Dos 30 participantes surdos, 15 são oralizados e 15 não-oralizados.

\subsection{COLETA DE DADOS}

Os sujeitos da pesquisa foram solicitados a responder a algumas perguntas de natureza pessoal a respeito da surdez (uso de prótese auditiva e realização de terapia fonoaudiológica para o desenvolvimento da linguagem oral e/ou escrita) e a responder a um questionário contendo perguntas acerca do seu dia-a-dia na escola.

\section{Questionário apresentado aos surdos}

1) Quais as dificuldades que você tem na escola por ser surdo?

2) Quais as dificuldades que você tem para se comunicar com os ouvintes?

3) Quais as situações em que você já sentiu preconceito por ser surdo?

4) Relate alguma situação engraçada por ser surdo. 
5) O que você sugere para facilitar a aprendizagem da língua portuguesa pelo surdo?

6) Que conselho você daria a um surdo que estivesse entrando na escola?

A ajuda dos intérpretes da escola foi solicitada sempre que surgiram dúvidas, especialmente com relação ao que o surdo queria expressar. Estes profissionais, no entanto, não interferiram no processo de escrita do surdo.

Os participantes ouvintes responderam a um questionário com a mesma quantidade de questões. As perguntas foram diferentes, adequadas ao fato de não serem surdos, no entanto, também versavam sobre o dia-a-dia na escola, focando a relação com os surdos.

\section{Questionário apresentado aos ouvintes}

1) Quais as diferenças que você percebe entre os colegas surdos e os ouvintes na sala de aula?

2) Quais as dificuldades que você tem para se comunicar com os surdos?

3) O que você sentiu quando começou a estudar com colegas surdos?

4) Quais as matérias em que os surdos têm mais dificuldade? Os professores modificam a sua forma de ensinar para facilitar a aprendizagem deles?

5) O que você sugere para facilitar a aprendizagem da língua portuguesa pelo surdo?

6) Que conselho você daria a um surdo que estivesse entrando na escola?

\subsection{ANÁLISE DE DADOS}

Os dados foram analisados em função da ocorrência de repetições na escrita entre os grupos, através do teste estatístico de Mann-Whitney, 
utilizado, no presente trabalho, para realizar a comparação de médias entre dois grupos independentes (surdos oralizados versus não-oralizados, surdos oralizados versus ouvintes e surdos não-oralizados versus ouvintes).

Em relação à ocorrência de repetição, foi realizada a avaliação da escrita do participante em função de ter apresentado alguma repetição ou não nas suas respostas.

No que se refere à frequência da repetição, foi realizada a contagem de situações em que o sujeito realizou a repetição de um termo ou expressão, classificando a repetição em baixa (quando foi realizada uma ou duas repetições de um termo ou expressão), média (três a quatro repetições) e alta frequência (mais de quatro repetições produzidas pelo sujeito).

A forma da repetição foi analisada em função de ser integral (quando o termo repetido foi igual à matriz) ou com variação (quando o termo repetido apresentava variação em relação à matriz).

Já a posição da repetição foi analisada em função de ser adjacente (quando o termo repetido encontrava-se próximo à matriz) ou distante (quando o termo repetido apresentava-se distante da matriz).

No que se refere à função da repetição, as repetições foram classificadas em função de compreensão (quando favorecia a geração de sequências mais compreensíveis), continuidade tópica (quando dava continuidade à organização tópica e auxiliava nas atividades interativas) e argumentatividade (quando promovia a geração de um discurso argumentativo).

A diferença entre as médias dos grupos foi considerada estatisticamente significante quando o p-valor fornecido pelo teste estatístico se mostrou igual ou menor que 0,05 ( $p \leq 0,05)$. O $p$-valor foi arredondado para até três casas decimais.

\subsection{CONSIDERAÇÕES ÉTICAS}

Anteriormente à realização da coleta dos dados, o projeto de pesquisa foi aprovado pelo Comitê de Ética em Pesquisa com Seres Humanos da Universidade Católica de Pernambuco sob o número $088 / 2005$. 


\section{RESULTADOS E DISCUSSÃO}

Todos os surdos oralizados participantes do estudo já fizeram uso de prótese auditiva. O tempo de utilização do aparelho de amplificação sonora variou entre cinco e dezessete anos. Já entre os surdos nãooralizados, apenas oito afirmaram haver feito uso de prótese auditiva, com tempo de uso que variou entre um e seis anos. Alguns surdos, no entanto, não souberam precisar o tempo de utilização da prótese.

Desta forma, mais surdos oralizados fazem ou fizeram uso de prótese auditiva em relação aos não-oralizados, além de ser o tempo de uso do equipamento, em geral, maior entre os oralizados. O menor tempo de utilização ou a não-utilização da prótese auditiva é compatível com o fato de não serem oralizados, pois, segundo Tye-Murray (1998), o não uso do equipamento de amplificação sonora individual dificulta ou, muitas vezes, impossibilita o acesso à modalidade oral da língua. Desta forma, quanto menor o tempo de uso do aparelho, menor é o contato do surdo com a língua oral e, consequentemente, menores serão suas habilidades linguísticas orais (BEVILACQUA; FORMIGONI, 2000; TURKOWSKI et al., 2003, BASTOS; FLEIG; NASCIMENTO, 2010).

A terapia fonoaudiológica para o desenvolvimento da linguagem oral e/ou escrita é (foi) realizada por doze surdos oralizados, por um período de tempo que variou entre dois e doze anos. Entre os surdos não-oralizados, nenhum fazia fonoterapia no momento, enquanto nove afirmaram tê-la realizado anteriormente. O tempo de realização de terapia dos surdos não-oralizados variou de três meses a cinco anos. Alguns surdos oralizados e não-oralizados não souberam fornecer a informação referente ao tempo de realização da terapia.

O fato de ser a terapia fonoaudiológica um importante instrumento para o desenvolvimento e otimização das habilidades linguísticas orais e escritas do surdo (BELTRÁN; VILLALOBOS, 1998) torna natural a verificação de que, em relação aos surdos oralizados, um maior número de surdos não-oralizados nunca realizou fonoterapia, além de nenhum fazê-la no momento da coleta dos dados. O fato de um maior número de surdos oralizados realizar ou ter realizado terapia fonoaudiológica e usar ou ter usado prótese auditiva em relação aos surdos não-oralizados permite a sugestão de que, possivelmente, aqueles 
sujeitos apresentam, de fato, habilidades linguísticas orais mais desenvolvidas que estes.

A partir da Tabela 1, verificou-se que, entre os três grupos, a maior ocorrência de repetições se deu na escrita dos surdos oralizados, seguidos pelos surdos não-oralizados e pelos ouvintes. Como a repetição, segundo Marcuschi (2006), é uma das estratégias de formulação textual mais presentes na oralidade, isso pode ter provocado o maior número desta marca entre os surdos oralizados em relação aos não-oralizados.

Apesar de ser uma característica da língua e um recurso que favorece as funções de natureza coesiva e argumentativa (SILVA, 2001), a repetição ainda é percebida de forma depreciativa (ANTUNES, 1994) nos usos da modalidade escrita, motivo pelo qual (hipoteticamente) se teria encontrado menor ocorrência na escrita dos ouvintes. Estes sujeitos estavam em processo de preparação para o ingresso na universidade, por meio do vestibular e, com isso, estariam desenvolvendo um padrão de escrita mais próximo da norma culta da língua portuguesa, em que as repetições são desprivilegiadas em função de outras estruturas gramaticais, como os pronomes relativos. A repetição é algo não desejado na escrita (RODRIGUES, 2008), especialmente no vestibular (RAMIRES, 2007).

Tabela 1 - Distribuição quantitativa dos participantes segundo o uso de repetições de qualquer tipo e função.

\begin{tabular}{|c|c|c|c|c|c|c|c|c|}
\hline & \multicolumn{2}{|c|}{ ORALIZADOS } & \multicolumn{2}{|c|}{ NÃO-ORALIZADOS } & \multicolumn{2}{|c|}{ OUVINTES } & \multicolumn{2}{|c|}{ TOTAL } \\
\hline & $\mathbf{N}$ & $\%$ & $\boldsymbol{N}$ & $\%$ & $\boldsymbol{N}$ & $\%$ & $\mathbf{N}$ & $\%$ \\
\hline Sim & 12 & 80,00 & 8 & 53,33 & 6 & 40,00 & 26 & 57,78 \\
\hline Não & 3 & 20,00 & 7 & 46,67 & 9 & 60,00 & 19 & 42,22 \\
\hline Total & 15 & 100,00 & 15 & 100,00 & 15 & 100,00 & 45 & 100,00 \\
\hline
\end{tabular}

Na Tabela 2, é apresentada a frequência de utilização da repetição pelos três grupos. Para isso, foram incluídos apenas os participantes que apresentaram repetição em sua produção textual. Como referido anteriormente, a frequência das repetições foi categorizada em baixa (uma a duas), média (três a quatro) e alta (mais de quatro repetições produzidas pelo sujeito). 
Foi verificado um percentual parecido de baixa frequência de uso da repetição entre os surdos oralizados $(66,67 \%)$ e os não-oralizados $(62,5 \%)$. Apesar disso, um surdo não-oralizado apresentou alta frequência de uso. Todos os ouvintes que manifestaram a repetição na escrita apresentaram baixa frequência de sua utilização. Isto pode ser, mais uma vez, explicado pela hipótese de estarem desenvolvendo um padrão de escrita mais próximo da norma culta da língua, em que a repetição, embora não seja proibida, só é permitida de modo restrito.

Tabela 2 - Distribuição quantitativa dos participantes segundo a frequência das repetições (de qualquer tipo).

\begin{tabular}{|c|c|c|c|c|c|c|c|c|}
\hline & \multicolumn{2}{|c|}{ ORALIZADOS } & \multicolumn{2}{|c|}{ NÃO-ORALIZADOS } & \multicolumn{2}{|c|}{ OUVINTES } & \multicolumn{2}{|c|}{ TOTAL } \\
\hline & $n$ & $\%$ & $n$ & $\%$ & $n$ & $\%$ & $n$ & $\%$ \\
\hline Baixa & 8 & 66,67 & 5 & 62,50 & 6 & 100,00 & 18 & 72,00 \\
\hline Média & 4 & 33,33 & 2 & 25,00 & 0 & 0 & 6 & 24,00 \\
\hline Alta & 0 & 0 & 1 & 12,50 & 0 & $\overline{0}$ & 1 & 4,00 \\
\hline Total & 12 & 100,00 & 8 & 100,00 & 6 & 100,00 & 25 & 100,00 \\
\hline
\end{tabular}

Foi percebida, através dos dados da Tabela 3, a prevalência das repetições integrais (cujo exemplo se encontra na Figura 1) sobre as repetições com variação (cujo exemplo se encontra na Figura 2). Segundo Marcuschi (1997) e Tannen (1987 apud KOCH et al., 2002), a repetição exata é mais rara na conversação, no entanto, os autores se referem à conversação oral, em função da entoação que se utiliza durante a fala. Eles afirmam ainda que, mesmo sendo repetida a informação, a entoação é diferente, o que faz com que se considere a ocorrência uma repetição com variação. Tendo em vista a ausência da entoação na escrita, nestes casos se considera a repetição como integral, por utilizar os mesmos termos em momentos diferentes.

Foram consideradas, para a Tabela 3, todas as repetições realizadas pelos sujeitos. Alguns realizaram mais de uma com formas diferentes, sendo classificados nas duas categorias. 
Tabela 3 - Distribuição quantitativa das repetições segundo a forma.

\begin{tabular}{|c|c|c|c|c|c|c|c|c|}
\hline & \multicolumn{2}{|c|}{ ORALIZADOS } & \multicolumn{2}{|c|}{ NÃO-ORALIZADOS } & \multicolumn{2}{|c|}{ OUVINTES } & \multicolumn{2}{|c|}{ TOTAL } \\
\hline & $n$ & $\%$ & $n$ & $\%$ & $n$ & $\%$ & $n$ & $\%$ \\
\hline Integral & 12 & 80,00 & 7 & 87,50 & 5 & 83,33 & 24 & 82,76 \\
\hline Variação & 3 & 20,00 & 1 & 12,50 & 1 & 16,67 & 5 & 17,24 \\
\hline Total & 15 & 100,00 & 8 & 100,00 & 6 & 100,00 & 29 & 100,00 \\
\hline
\end{tabular}

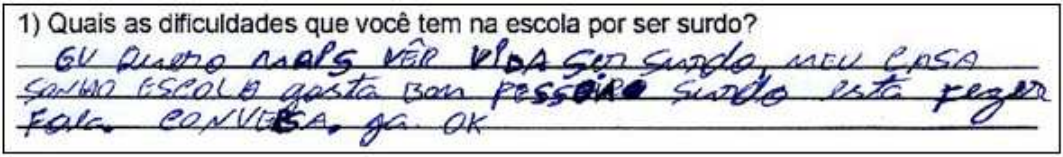

Figura 1 - Exemplo de repetição integral por um surdo não-oralizado, em que o termo 'surdo' ocorre duas vezes.

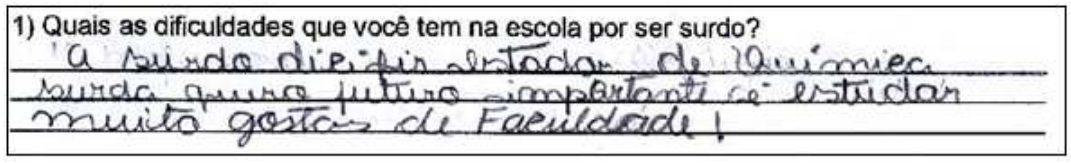

Figura 2 - Exemplo de repetição com variação por um surdo não oralizado, em que foi feito uso dos termos "surdo" (1 $1^{a}$ linha) e "surda" ( $2^{a}$ linha).

Com relação à posição do termo repetido na construção textual, percebe-se, a partir da Tabela 4, que a ocorrência de repetições adjacentes (cujo exemplo se encontra na Figura 3) foi maior do que as distantes (cujo exemplo se encontra na Figura 4) nos três grupos analisados. As repetições adjacentes foram realizadas por $75 \%$ dos surdos oralizados, $60 \%$ dos surdos não-oralizados e $83,33 \%$ dos ouvintes.

De forma semelhante à Tabela 3, alguns sujeitos realizaram mais de uma repetição em posições diferentes na construção textual, sendo classificados nas duas categorias. 
Tabela 4 - Distribuição quantitativa das repetições segundo a posição na construção textual.

\begin{tabular}{|c|c|c|c|c|c|c|c|c|}
\hline & \multicolumn{2}{|c|}{ ORALIZADOS } & \multicolumn{2}{|c|}{ NÃO-ORALIZADOS } & \multicolumn{2}{|c|}{ OUVINTES } & \multicolumn{2}{|c|}{ TOTAL } \\
\hline & $n$ & $\%$ & $n$ & $\%$ & $n$ & $\%$ & $\mathbf{N}$ & $\%$ \\
\hline Adjacente & 12 & 75,00 & 6 & 60,00 & 5 & 83,33 & 23 & 71,87 \\
\hline Distante & 4 & 25,00 & 4 & 40,00 & 1 & 16,67 & 9 & 28,13 \\
\hline Total & 16 & 100,00 & 10 & 100,00 & 6 & 100,00 & 32 & 100,00 \\
\hline
\end{tabular}

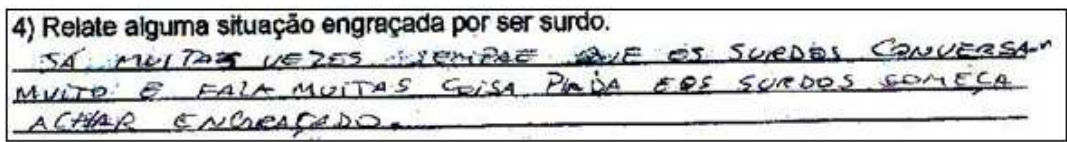

Figura 3 - Exemplo de repetição adjacente, em que o surdo escreve três vezes o termo 'muito' de forma integral e com variação ("muitas vezes", "conversam muito" e "fala muitas coisa").

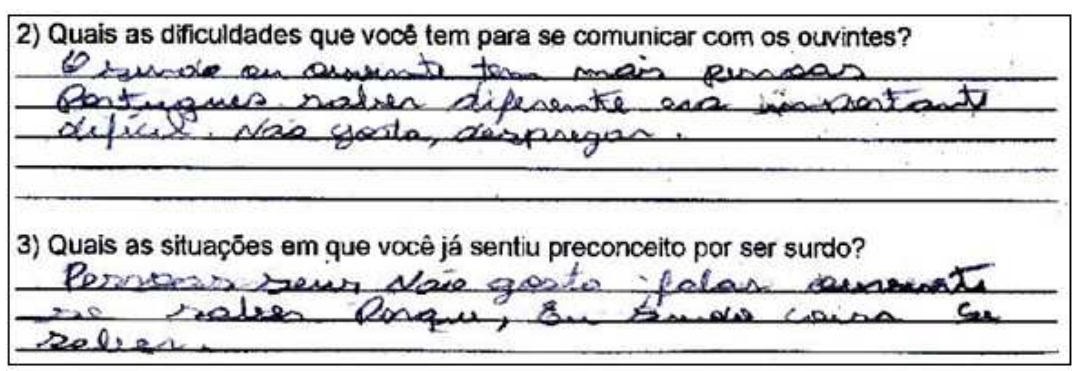

Figura 4 - Exemplo de repetição distante, em que o surdo escreve 'não gosta', na terceira linha da pergunta 2 e na primeira linha da pergunta 3 .

Para a classificação das repetições quanto à função (Tabela 5), foram consideradas as categorias destacadas por Marcuschi (1997) no plano discursivo: compreensão (intensificação ou esclarecimento), continuidade tópica (amarração, introdução e reintrodução) e argumentatividade (reafirmação, contraste e contestação).

Com relação à função exercida pela repetição na produção linguística, verificou-se predomínio da função de continuidade tópica no grupo dos surdos oralizados e dos não-oralizados, enquanto que, entre os ouvintes, predominou a função de compreensão. 
Segundo Marcuschi (1997), a continuidade tópica propicia a manutenção da "fluência discursiva". Pelo fato de não possuírem domínio da língua portuguesa, os surdos podem lançar mão de repetições com esta função para aproximar a escrita da língua padrão do país, já que a sua escrita é fortemente influenciada pela língua de sinais, sua primeira língua (L1). Já entre os ouvintes prevaleceu a função de compreensão. Estes sujeitos apresentam domínio da língua portuguesa, ao menos na modalidade oral, e, com isso, o recurso da repetição lhes serve para facilitar, aos leitores, a compreensão do enunciado linguístico (MARCUSCHI, 2006).

A função argumentativa da repetição surgiu apenas em um participante ouvinte. Este tipo de função possivelmente não surgiu com maior frequência entre os ouvintes e não ocorreu entre os surdos pelo fato de as perguntas serem objetivas e, com isso, não propiciarem a possibilidade de monitorar a tomada de turno e ratificar o papel do interlocutor.

Alguns sujeitos realizaram mais de uma repetição com funções diferentes, sendo classificados em mais de uma categoria.

Tabela 5 - Distribuição quantitativa das repetições segundo a função.

\begin{tabular}{|c|c|c|c|c|c|c|c|c|}
\hline & \multicolumn{2}{|c|}{ ORALIZADOS } & \multicolumn{2}{|c|}{ NÃO-ORALIZADOS } & \multicolumn{2}{|c|}{ OUVINTES } & \multicolumn{2}{|c|}{ TOTAL } \\
\hline & $n$ & $\%$ & $n$ & $\%$ & $n$ & $\%$ & $n$ & $\%$ \\
\hline Comp & 8 & 44,44 & 3 & 33,33 & 5 & 71,42 & 16 & 47,06 \\
\hline Cont & 10 & 55,56 & 6 & 66,67 & 1 & 14,29 & 17 & 50,00 \\
\hline Argum & 0 & 0 & 0 & 0 & 1 & 14,29 & 1 & 2,94 \\
\hline Total & 18 & 100,00 & 9 & 100,00 & 7 & 100,00 & 34 & 100,00 \\
\hline
\end{tabular}

Legenda: Comp $=$ Compreensão; Cont $=$ Continuidade tópica; Argum = Argumentatividade

Os resultados apresentados na Tabela 6 mostram uma diferença significativa $(p=0,008)$ entre a ocorrência de repetição entre o grupo dos surdos oralizados e o dos ouvintes. Por outro lado, conforme se observa na Tabela 7 , não há diferença significativa $(\mathrm{p}=0,197)$, considerando o mesmo aspecto, entre os grupos dos surdos oralizados e o dos não-oralizados. De acordo com a Tabela 8, inexiste diferença significativa $(p=0,406)$ entre ocorrência de repetição no grupo dos surdos não-oralizados e no dos ouvintes. 
Tabela 6 - Resultados obtidos com a aplicação do Teste de Mann-Whitney entre os grupos dos surdos oralizados e o dos ouvintes. São apresentadas as médias da quantidade de repetições utilizadas pelos grupos.

\begin{tabular}{c|c|c}
\hline & ORALIZADOS & OUVINTES \\
\hline Média & 2,667 & 0,533 \\
\hline p-valor & \multicolumn{2}{|c|}{0,008} \\
\hline
\end{tabular}

Tabela 7 - Resultados obtidos com a aplicação do Teste de Mann-Whitney entre os grupos dos surdos oralizados e o dos não-oralizados. São apresentadas as médias da quantidade de repetições utilizadas pelos grupos.

\begin{tabular}{c|c|c}
\hline & ORALIZADOS & NÃO-ORALIZADOS \\
\hline Média & 2,667 & 1,2 \\
\hline p-valor & \multicolumn{2}{|c}{0,197} \\
\hline
\end{tabular}

Tabela 8 - Resultados obtidos com a aplicação do Teste de Mann-Whitney entre os grupos dos surdos não-oralizados e o dos ouvintes. São apresentadas as médias da quantidade de repetições utilizadas pelos grupos.

\begin{tabular}{c|c|c}
\hline & NÃO-ORALIZADOS & OUVINTES \\
\hline Média & 1,2 & 0,533 \\
\hline p-valor & \multicolumn{2}{|c|}{0,406} \\
\hline
\end{tabular}

De forma geral, os achados do presente estudo diferem dos resultados de Andrade et al. (2006), que não verificaram repetição na escrita de um surdo oralizado. A diferença pode ter como causa o fato de que, no trabalho citado, houve a participação de apenas um sujeito surdo.

\section{CONSIDERAÇÕES FINAIS}

A análise do material permite concluir que, de forma geral, as repetições se mostraram presentes na escrita dos surdos oralizados e dos não-oralizados, assim como dos ouvintes. A ocorrência desta marca de oralidade se deu em maior quantidade pelos surdos oralizados, seguidos pelos surdos não-oralizados e pelos ouvintes. Com relação à frequência, forma e posição, prevaleceu a repetição de baixa frequência, integral e adjacente, nos três grupos. 
Os surdos (tanto os oralizados quanto os não-oralizados) produziram mais repetição com função de continuidade tópica, enquanto que os ouvintes a utilizaram, principalmente, com função de compreensão. Acredita-se que o maior uso de repetição com função de continuidade tópica pelos surdos aconteça pela dificuldade que eles têm em apresentar coesão textual. Desta forma, estes sujeitos usariam o artifício da repetição para dar continuidade à organização tópica e auxiliar nas atividades interativas com o leitor.

Foi verificada diferença estatisticamente significativa entre o uso de repetições entre os surdos oralizados e os ouvintes, com maior uso de repetições por aquele grupo.

Diante do exposto, a pesquisa mostra ocorrência do continuum oralidade-escrita nos surdos oralizados e não-oralizados, assim como ocorre naturalmente no ouvinte.

Este estudo sugere que, pelo fato de as marcas de oralidade constituírem um fator de coesão textual, o uso destes recursos pode se configurar em mais uma frente de trabalho com a escrita do surdo, especialmente o não-oralizado, a fim de estimular a coesão das produções desses sujeitos.

\section{REFERÊNCIAS}

ANDRADE, W. T .L. et al. Marcas de oralidade na escrita de três sujeitos com diferentes características de linguagem. In: ENCONTRO NACIONAL SOBRE AQUISIÇÃO DE LINGUAGEM (ENAL), 7., Porto Alegre, RS. Anais... Porto Alegre: PUCRS, 2006. p. 227.

ANTUNES, I. C. O papel da repetição na construção textual. ABRALIN, n. 15, p. 131-138, jul. 1994.

BASTOS, F. N.; FLEIG, R.; NASCIMENTO, I. B. Análise das habilidades auditivas em uma criança deficiente auditiva oralizada e portadora de HIV: estudo de caso. Revista CEFAC, São Paulo, v. 12, n. 4, p. 700-8, jul./ago. 2010.

BELTRÁN, L. F.; VILLALOBOS, P. B. E1 niño sordo de edad preescolar: identificación, diagnostico y tratamiento - guía para padres, médicos y maestros. 2. ed. México: Trillas, 1998.

BEVILACQUA, M. C.; FORMIGONI, G. M. P. Audiologia Educacional: uma opção terapêutica para a criança deficiente auditiva. Carapicuíba: Pró-Fono, 2000. 
BRASIL. Ministério da Educação e do Desporto. Secretaria de Educação Especial. Programa de capacitação de recursos humanos do ensino fundamental: A educação dos surdos. vol. II. Brasília: MEC/SEESP, 1997.

BUENO, J. G. S. Surdez, linguagem e cultura. Cadernos CEDES, v. 46, n. 19, p. 41-56, set. 1998.

CALADO, L. C. Variações linguísticas no contexto de escolas públicas: fatores intervenientes. 2004. 112 f. Dissertação (Mestrado em Ciências da Linguagem) - Universidade Católica de Pernambuco, Recife, 2004.

CAVALCANTE, M. C. B.; MARCUSCHI, B. Formas de observação da oralidade e da escrita em gêneros diversos. In: MARCUSCHI, L. A.; DIONÍSIO, A. P. Fala e escrita. Belo Horizonte: Autêntica, 2005. p. 123-143.

CICCONE, M.M.C. A pessoa surda e implicações da surdez. In: CICCONE, M.M.C. Comunicação Total - introdução, estratégia, a pessoa surda. 2. ed. Rio de Janeiro: Cultura Médica, 1996. p. 18-23.

COLLINS, J.; MICHAELS, S. A fala e a escrita: estratégias de discurso e aquisição da alfabetização. In: COOK-GUMPERZ, J. (Org.) A construção social da alfabetização. Porto Alegre: Artes Médicas, 1991. p. 242-258.

COUTO-LENZI, A. Percepção da fala: teste. Rio de Janeiro: Timing, 1997.

FELIPE, T. A. O signo gestual-visual e sua estrutura frasal na língua de sinais dos centros urbanos do Brasil (LSCB). 1988. 105 f. Dissertação (Mestrado em Linguística) - Universidade Federal de Pernambuco, Recife, 1988.

FERNANDES, E. Problemas linguísticos e cognitivos dos surdos. Rio de Janeiro: Agir, 1990.

Linguagem e surdez. Porto Alegre: Artmed, 2003.

FERREIRA-BRITO, L. Integração social \& educação de surdos. Rio de Janeiro: Babel, 1993.

GOLDFELD, M. A criança surda: linguagem e cognição numa perspectiva sócio-interacionista. 2. ed. São Paulo: Plexus, 2002.

HARRISON, K. M. P.; LODI, A. C. B.; MOURA, M. C. Escolas e escolhas: processo educacional dos surdos. In: LOPES FILHO, O. (Ed.) Tratado de Fonoaudiologia. São Paulo: Roca, 1997. p. 359-400.

JUBRAN, C. C. A. S. Tópico discursivo. In: JUBRAN, C. C. A. S.; KOCH, I. G. V. Gramática do português culto falado no Brasil. Campinas: UNICAMP, 2006. p. 89-132. 
KOCH, I.G.V. et al. Aspectos do processamento do fluxo de informação no discurso oral dialogado. In: CASTILHO, A. T. (Org.) Gramática do português falado. 4. ed. vol. 1. Campinas: UNICAMP, 2002. p. 121-54.

LACERDA, C.B.F. Um pouco da história das diferentes abordagens na educação de surdos. Cadernos CEDES, v. 46, n. 19, p. 68-80, set. 1998.

A prática pedagógica mediada (também) pela língua de sinais:

trabalhando com sujeitos surdos. Cadernos CEDES, v. 50, n. 20, p. 70-83, abr. 2000 .

LANE, H. A máscara da benevolência: a comunidade surda amordaçada. Lisboa: Horizontes pedagógicos, 1992.

MARCUSCHI, L.A. Contextualização e explicitude na relação entre fala e escrita. In: ENCONTRO NACIONAL SOBRE LÍNGUA FALADA E ENSINO, 1., Maceió, AL. Anais..., Maceió: UFAL, 1995. p. 27-48.

A repetição na língua falada como estratégia de formulação textual. In: KOCH, I.G.V. (Org.) Gramática do português falado. 2. ed. vol. 6. Campinas: UNICAMP/ FAPESP, 1997. p. 95-129.

Nove teses para uma reflexão sobre a valorização da fala no ensino da língua. Revista da ANPOLL, v. 4, n. 3, p. 325-32. 1998.

Letramento e oralidade no contexto das práticas sociais e eventos comunicativos. In: SIGNORINI, I. (Org.) et al. Investigando a relação oral/escrito e as teorias do letramento. Campinas: Mercado das Letras, 2001. p. 23-74.

. A presença da repetição na fala e algumas perspectivas de tratamento. Investigações: Linguística e Teoria Literária, v. 2, p. 31-47, dez. 2002.

. Da fala para a escrita: atividades de retextualização. 5. ed. São Paulo: Cortez, 2004.

Oralidade e letramento como práticas sociais. In: MARCUSCHI, L.A.; DIONÍSIO, A.P. Fala e escrita. Belo Horizonte: Autêntica, 2005. p. 31-55.

Repetição. In: JUBRAN, C. C. A. S.; KOCH, I. G. V. Gramática do português culto falado no Brasil. Campinas: UNICAMP, 2006. p. 219-254.

MONREAL, S.T. (Coord.) et al. Deficiencia auditiva: aspectos psicoevolutivos y educativos. Granada: Aljibe, 1995.

PERDONCINI, G. Prefácio. In: PERDONCINI, G.; COUTO-LENZI, A. Audição é o futuro da criança surda. Rio de Janeiro: Aipeda, 1996. p. 7-10. 
PERDONCINI, G.; COUTO-LENZI, A. Audição é o futuro da criança surda. Rio de Janeiro: Aipeda, 1996.

QUADROS, R.M. Linguística contrastiva - o ensino da língua escrita para surdos via língua de sinais. In: CONGRESSO LATINO-AMERICANO DE BILINGUISMO PARA SURDOS. 2., Rio de Janeiro, 1993.

Educação de surdos: a aquisição da linguagem. Porto Alegre: Artes Médicas, 1997.

RAMIRES, V. Redação no vestibular: avaliação subjetiva e competência linguística. In: SIMPÓSIO INTERNACIONAL DE ESTUDOS DE GENEROS TEXTUAIS (SIGET), 4., Tubarão, SC. Anais... 2007. v. 1, p. 1988-2000.

RODRIGUES, M. A. N. A prática da escrita na escola: uma análise do processo ao produto. 2008. 116 f. Dissertação (Mestrado em Linguística) Centro de Ciências Humanas, Letras e Artes, Universidade Federal da Paraíba, João Pessoa, 2008.

SALLES, H. M. M. L. et al. Ensino de língua portuguesa para surdos: caminhos para a prática pedagógica. Brasília: MEC/SEESP, 2004.

SÁNCHEZ, C. M. La increíble y triste historia de la sordera. Caracas: CEPROSORD, 1990.

SANTOS, L. H. M.; DIAS, M. G. B. B. Compreensão de textos em adolescentes surdos. Psicologia: teoria e pesquisa, v. 14, n. 3, p. 241-249, set./dez. 1998.

SANTOS, M. T. M.; NAVAS, A. L G. P. Distúrbios de leitura e escrita. In: SANTOS, M. T. M.; NAVAS, A. L. G. P. (Org.) Distúrbios de leitura e escrita: teoria e prática. Barueri: Manole, 2002. p. 27-74.

SILVA, D. E. G. A repetição em narrativas de adolescentes: do oral ao escrito. Brasília: UnB/Plano, 2001.

SKLIAR, C.; MASSONE, M.; VEINBERG, S. El acceso de los niños sordos al bilinguismo y al biculturalismo. Revista Infancia y Aprendizaje, Madrid, v. 2, n. 69/70, p. 85-100. 1995.

SOUZA, R. M. Língua de sinais e língua majoritária como produto de trabalho discursivo. Cadernos CEDES, v. 46, n. 19, p. 57-67, set. 1998.

TANNEN, D. Repetition and variation as spontaneous formulaicity in conversation. Georgetown University, 1985 (mimeo). 
TURKOWSKI, A. P. F. et al. Estudo da efetividade da abordagem aurioral na reabilitação em paciente com perda auditiva neurossensorial moderada, Iniciação Científica Cesumar, Maringá, v. 5, n. 1, p. 23-8, jan./jun. 2003.

TYE-MURRAY, N. Foundations of aural rehabilitation: children, adults and their family members. San Diego: Singular, 1998.

Recebido em: 07/04/11. Aprovado em: 01/07/11.

Title: The use of repetition in the deafs' writing

Authors: Wagner Teobaldo Lopes de Andrade; Marígia Ana de Moura Aguiar; Francisco Madeiro Abstract: Writing is an important means of communication for the deaf with his/her peers, as well as with the non-deaf as a result of their difficulty in developing oral language. Considering that oral cues are directly related to text cohesion, this study aimed to investigate the use of repetition in the writing of the deaf. Fifteen oralized deaf speakers, fifteen non-oralized deaf speakers and fifteen hearing speakers answered to a questionnaire which underwent both quantitative and qualitative analysis as related to occurrence, typology, form, position and function of repetition. Results showed that the three groups of participants used repetition in writing. The two groups of deaf speakers showed, mainly, low frequency, integral and adjacent repetitions in writing. The oralized speakers showed more repetitions with comprehension function while the non-oralized used repetition especially with topic continuity function. The conclusion of this research is that similar to hearers the relation between orality and writing is present in the deaf, even without natural access to orality.

Keywords: Speech. Writing. Repetition. Deafness.

Titulo: El uso de la repetición em la escritura por los surdos

Autores: Wagner Teobaldo Lopes de Andrade; Marígia Ana de Moura Aguiar; Francisco Madeiro

Resumen: La escritura es una importante forma de comunicación de los sordos tanto con sus pares como con los oyentes, dada su dificultad en desarrollar la oralidad. Por estar las marcas de oralidad directamente relacionadas a la cohesión textual, este estudio objetivó investigar el uso de repeticiones en la escritura de sordos. Quince sordos oralizados, quince sordos no-oralizados y quince oyentes respondieron a un cuestionario analizado cuantitativa y cualitativamente en función de la ocurrencia, tipología, forma, posición y función de las repeticiones. Los tres grupos utilizaron la repetición en la escritura. Los dos grupos de sordos presentaron, mayoritariamente, baja frecuencia en la repetición, integral y adyacente, en la escritura. Los oralizados realizaron más repeticiones con función de comprensión, mientras que los nooralizados las realizaron, especialmente, con función de continuidad tópica. Se concluye que, tal como pasa con los oyentes, la relación oralidad/escritura ocurre en los sordos, aunque ellos no hayan tenido acceso natural a la oralidad de la lengua. Y esta relación ocurre independientemente de ellos haber sido oralizados o no.

Palabras clave: Habla. Escritura. Repetición. Sordera. 